\title{
Digitisation and Language Technologies in the Learning Process of Information Sciences - Approaching the EU Standards
}

\author{
Stančić, Hrvoje, Ph.D.
}

Assistant professor, hrvoje.stancic@zg.t-com.hr

Seljan, Sanja, Ph.D.

\section{Assistant professor, sseljan@ffzg.hr}

Lasic-Lazic, Jadranka Ph.D.

Full professor, jlazic@ffzg.hr

Department of Information Sciences, Faculty of Humanities and Social Sciences, University of Zagreb, Croatia

\section{Summary}

The authors discuss the need for digital content that represents basis for multilingual and multicultural environment enabling multilingual information retrieval and computerassisted translation. The authors examine the learning process of information sciences at Croatian university level education-in correlation with the European context. The problem of multilingualism in the information society has been investigated in the context of the Bologna process and the requirement of the student mobility as well as in the context of different EU standards, action plans and framework programmes. Further, the authors describe e-learning environment implemented at the university level, give the results of the research made among the users of the system, and discuss the potential problems considering the digitisation in the process of preparation of the materials in order to enable the application of language technologies for automatic translation suitable in the student mobility environment. 
Key words: language technologies, digitisation, translation, multilingual environment, Croatia, student mobility, Bologna process 


\section{Introduction}

The ambition to implement educational and organisational changes in line with the educational policy statements in Croatia and the Bologna process, respecting European standards regarding use of ICT, alliance with industry, internal and external evaluation process, team work, mobility programs have resulted by first steps towards knowledge society. Department of Information Sciences, as one of 23 departments that constitute the Faculty of Humanities and Social Sciences of the University of Zagreb, Croatia can be studied as part of two majors (another study group is mainly philological) or as the principal study group, where besides classic knowledge regarding programming techniques, mathematics, databases and information retrieval, special knowledge is offered to students. Regarding its specific position special attention is given to the specific knowledge regarding language technologies, lexicography, knowledge management, digitisation process, and elearning. Offering nearly 80 undergraduate programs to 6,100 students, as well as a number of postgraduate programs, the Faculty's rich possibilities are comparable to those of a small university.

The need for integration of the university into its economic environment is perceived in the Croatian context, but also in international relations. As the university still remains the principal provider of well-educated professionals and experts, alliance with industry and practical solutions, besides its scientific research, is needed.

Although willing to participate in the process of harmonisation and progress, several factors have caused significant problems. Besides lack of space and time for education process, technology has transformed ways of teaching and learning. Therefore, a complete technological equipment of suitable quality and quantity should be at disposal in order to use it in an appropriate way for individual work or team project, but also for practice of the application of presentation and communication skills. The e-learning environment Omega that has been recently introduced enables students an easier access to the learning materials in the electronic form. Therefore, the process of digitisation plays an important role in the preparation of the materials.

\section{Multilingualism in the Information Society}

The need for multilingual information retrieval, translation, communication and language learning are obvious in the EU countries, because of the principal requirements of multilingualism and the possibility to access the documents in various languages. Due to the need for multilingual communication, language technologies have become one of the key factors for European industry, education and business. The policy for language preservation, 
the possibility to access information on various languages, and the need for fast and consistent translations are pointed out and promoted through different actions of education, training and research.

With 21 official languages (from the 1st January 2007) and 420 translation directions, an incredible effort has been made to enable cross-lingual activities, stimulating communication, economy development, and harmonization of education. Although not yet part of EU, the need for quick translation, localisation and multilingual communication is obvious in numerous Croatian agencies, private and state companies, government, business, education, culture, entertainment and any kind of cooperation activities. Therefore, an appropriate higher education should answer to the national need and international standards. In order to be used and taught and to be integrated one day into multilingual environment, it is necessary to create electronically available Croatian language resources and to adopt EU standards regarding language tools and resources, data exchange, translation tools, educational and professional demands.

The EU has pointed out through action plans, framework programmes, IST (Information Society Technologies) programme, and strategy plans the importance of human language technologies and multilingualism. Understanding and communication has become desirable life-skill for every European citizen. EU has committed itself to undertake 45 new actions to promote language learning, language diversity, mobility and international partnership.

In the Framework Strategy for Multilingualism the Commission has three aims:

- to encourage language learning and promote linguistic diversity in society,

- to promote healthy multilingual economy, and

- to give citizens access to EU legislation, procedures and information in their own language in order to promote multilingualism in the information society and media industries.

The EU research activities, organized into "Framework Programmes for Research and Technological Development” focus on European added value. Language technologies were integral part of the "Multimodal Interfaces Strategic Objective", aiming to create natural and user-friendly human-computer interfaces for tomorrow's technologies, according to the information on "Languages and Europe" web-portal. The FP7 aims to reinforce research and development activities with special focus on machine translation and interpretation technologies, according to the "Framework Strategy for Multilingualism". Several EU programmes (eContent, eContentplus, Media and eLearning) support multilingual digital content and knowledge.

Following the European tendencies, but also because of rich Croatian language history and because of very old and valuable communication with European countries, the Croatian higher education policy tends to accomplish the mentioned aims in the educational 
process as well as through the research projects. Besides cultural aspect, business needs for cooperation, quick translation and the economic side of translation should be also taken into account. Apart from direct cost of translation, there are numerous hidden costs, such as e.g. localisation of a product, software or web site.

\section{Changes at the Faculty of Humanities and Social Sciences}

a) Curriculum changes

In order to be able to participate in the multilingual communication, necessity for building the Croatian linguistic resources are obvious in international communication. Creation of linguistic resources such as online dictionaries and thesauri, translation memories, terminology databases, software and tools for localisation and modules to include Croatian into machine translation system (EC Systran), respecting standard formats and organisation principles, would enable integration into European context. Although not yet part of the EU, some preparatory steps have been undertaken in order to start with organisational, educational, scientific and professional changes.

Regarding integration of the EU standards and the Bologna requirements into curriculum, numerous courses on human language technologies and digitisation have been offered at undergraduate level at the Department of Information Sciences of the Faculty of Humanities and Social Sciences such as "Machine Translation”, "Computer-Assisted Language Learning”, “Digitisation and Migration of Documents”, “Digital Archives”, "Preservation of Electronic Materials" and numerous courses following European tendencies at postgraduate level, e.g. "Machine-Assisted Translation Tools", "Language Databases in Lexicography and Encyclopedistics”, “Technology in Language Learning” and “Authenticity of Electronic Records”, etc. The courses have been adapted according to the Bologna requirements and integrated in the professional surroundings.

b) The Bologna process and e-learning

The Croatia started with the Bologna process in the academic year 2005/2006. The Bologna process required, among other things, smaller groups of students. Therefore we ended up with much more student groups than before. This speeded up the instalment and encouraged the use of an e-learning system at the Faculty of Humanities and Social Sciences, University of Zagreb. After serious testing of many different e-learning solutions within the 
project "Organisation of Information and Knowledge in the e-Learning Environment" we decided to use the open-source Moodle solution which we named Omega (the last e-learning solution you'll ever have to choose). Nowadays the system is widely accepted at the Faculty and the interface is translated into the Croatian language. As of October 2006 it is used by over 170 professors and teaching assistants and more than 2,500 students. There are over 180 courses available. Several other instalments followed in Croatia.

The system is used as an addition to the traditional way of teaching and learning, i.e. the idea was not to form the full distant learning solution although the system allows it but to reach the students in the electronic environment and take the best the solution. Therefore, at the course level, the students can download lecture presentations, additional texts, photographs or any other kind of teaching materials. They receive announcements, participate in the discussion forums, work in groups, participate in the creation of thematic dictionaries etc. They are also required to upload seminars and assignments, and their knowledge is to the certain degree tested through the system.

Although the system is functioning well and the atmosphere around it is very positive both among professors and students, the question is what can we, as professors, ask the students to do and in what timeframe. What can be expected from the students on the technological level? It is very important to know the users in order to adjust the expectations or to be sure that all users have certain standard and can deliver the requirements within the time limit. Furthermore, since one of the driving factors of the Bologna process is the idea of student mobility (on the advanced level of implementation every student is required to study at least one semester at some other university) we have to be prepared for accepting the foreign language speaking students.

\section{Research of the users}

In light of this, during the last five years we have questioned the first year students of the Study of Information Sciences on the technology they use, their knowledge of a basic set of applications as well as their habits considering the electronic environment. We have tried to learn about our users before we introduce them with the Omega e-learning system in order to know what level of usage can be expected from them and to decide on a minimum set of standard requirements they have to accept and apply to.

The following charts are excerpts from the research. They show the trends among the students who enrol the Study of Information Sciences at the Faculty of Humanities and Social 
Sciences in the combination with any other study at the Faculty. It can be concluded that the results shown here describe above average student since it is more likely that the average student of the Study of Information Sciences has better technical prerequisites and better IT relevant habits than an average student who is not the student of the Study of Information Sciences. Therefore the standards that we impose upon students of information sciences may be rather demanding for the average students. That fact should be taken into account while deciding upon the minimum set of standards according to the results shown here.

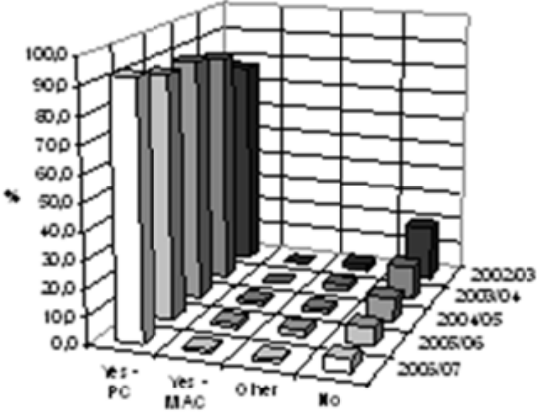

Chart 1: The number of students owing computer.

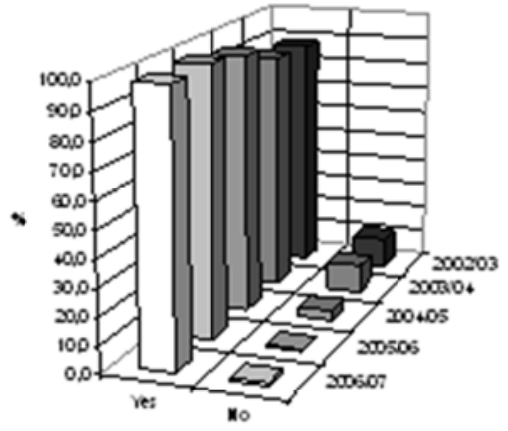

Chart 2: Students' Internet usage. 


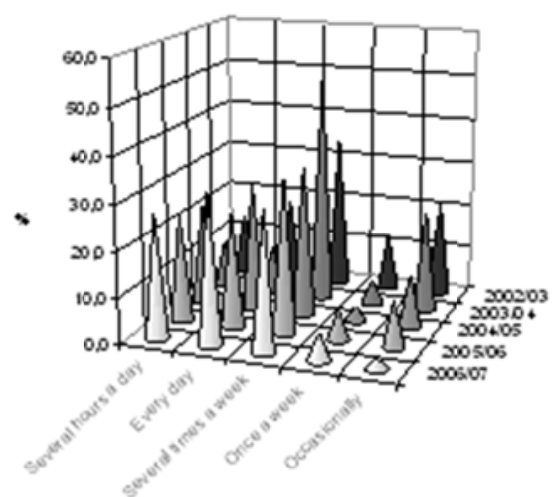

Chart 3: The frequency of student's Internet usage



Chart 5: The percentage of students having email address

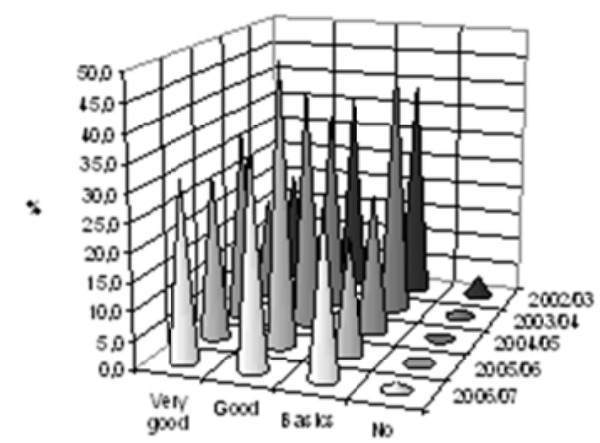

Chart 7: Students' assessment of their knowledge of MS Windows OS.



Chart 4: Access to Internet.



Chart 6: The percentage of students having personal web-page

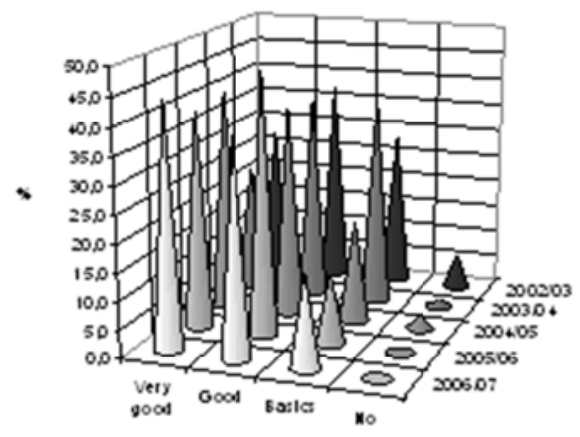

Chart 8: Students' assessment of their knowledge of MS Word.

The results show not only that every generation of the students of information sciences own more computers, but that their habits of Internet and e-mail usage change constantly towards everyday usage. It is also significant that nowadays $25 \%$ of them are using notebook 
computers since we have recently installed a wireless network at the Faculty. This means that the content in the e-learning system is more easily available to them.

\section{Student mobility, digitisation and language technologies}

Let us concentrate on one important and influencing requirement of the Bologna process - the student mobility requirement. As mentioned before, students will be required to enrol courses of their interest of other studies, faculties or universities, possibly in other countries. By the reciprocity rule, other students will be able to choose among the courses at the Faculty of Humanities and Social Sciences as well. The language could be one of the possible barriers. In our opinion, this possible obstacle could be diminished by the appropriate usage of information technology, by the appropriate preparation of the teaching materials, and by the usage of the translation technologies.

Considering the information technology factor it should be said that the foreign students who use the e-learning system Omega could choose among a great number of possible interface languages. Therefore this requirement has been dealt with by the appropriate choice of the e-learning system which enables this feature, and which is opensource based. Because of its wide acceptance, the community of users translate the interface into different languages. Currently it is possible to choose among 65 different interface languages.

Preparation of the teaching materials is a little bit more complicated since professors prepare them on their own. Not all of them are equally experienced and skilful with the information technology. Any file format can be uploaded as a teaching material but not all formats are suitable for the automatic language translation. Some of the digitally born materials, e.g. texts and textual PowerPoint slides, are more suitable than others, e.g. some PDF materials, or not appropriately digitised materials. Therefore, if the materials are to be digitised a whole range of questions should be answered first. Some of them could be:

- Is the level of support among the users appropriate?

- Do the standards being used meet established standards, producing materials of appropriate quality?

- Have copyright permissions been obtained and rights issues addressed? 
- Does the metadata conform to agreed standards?[1]

Other issues deal with the appropriate digitisation techniques important for the preparation of the quality teaching materials. The textual materials should be prepared in order to enable further manipulation which could be a great help and a step forward towards the easier student mobility into the multilingual teaching and learning environment.

\section{Conclusion}

Following the international tendencies regarding multilingual digital content and knowledge, important steps at university level have been undertaken in order to preserve cultural heritage through the process of digitisation, and to prepare textual materials for further processing, e.g. knowledge management, cross-linguistic retrieval, indexing or machine translation. Croatia, as a rather small country has to analyse and adopt EU standards regarding digitisation, creation of language resources, language learning and data exchange. The use of ICT in educational process, new types of organisational forms, and professional changes are some answer to new types of jobs that demand interdisciplinary knowledge, language skills, computer literacy and flexibility in problem solving.

The presented results are outcomes of the scientific projects "Information Technology in Computer-Assisted Translation of Croatian and in e-Language Learning” and “Organisation, Management and Knowledge Dissemination in Electronic Educational Environment” undertaken with the support of Ministry of Science, Education and Sport of the Republic of Croatia.

\section{References}

A New Framework Strategy for Multilingualism. Communication from the Commission to the Council, the European Parliament, the European Economic and Social Committee and the Committee of the Regions. Commission of the European Communities. Brussels, 22.11.2005. 
Ayris, Paul. Guidance for Selecting Materials for Digitisation, Joint RLG and NPO Conference: Guidelines for Digital Imaging, 1999. http://www.rlg.org/legacy/preserv/joint/ayris.html

Human Language Technologies for Europe. http://www.tc-star.org/pubblicazioni/D17_HLT_ENG.pdf

Moodle. http://www.moodle.org/

Seljan, Sanja. Information Technology in Machine Translation and in e-Language Learning of Croatian. Proceedings of the I International Conference on Multidisciplinary Information Sciences and Technologies, InSciT2006. Open Institute of Knowledge, Badajoz, Spain, 2006, vol. II, pp. 359-363.

Seljan, Sanja; Pavuna, Damir. Why Machine-Assisted Translation (MAT) Tools for Croatian? Proceedings of $28^{\text {th }}$ International Information Technology Interfaces Conference, ITI 2006. Cavtat/ Dubrovnik, 2006, pp. 469-475

Translating for a multilingual community. Directorate-General for Translation of the European Commission (DGT), April 2005.

http://europa.eu.int/comm/dgs/translation/bookshelf/brochure_en.pdf

Translation tools and Workflow. Directorate-General for Translation of the European Commission (DGT), April 2005.

http://europa.eu.int/comm/dgs/translation/bookshelf/toolsandworkflowen.pdf

[1] Ayris, Paul, Guidance for Selecting Materials for Digitisation, Joint RLG and NPO Conference: Guidelines for Digital Imaging, 1999., http://www.rlg.org/legacy/preserv/joint/ayris.html 